Cambridge University Press

978-0-521-83407-0 - Cognitive Limitations in Aging and Psychopathology

Edited by Randall W. Engle, Grzegorz Sedek, Ulrich von Hecker and Daniel N. Mcintosh

Frontmatter

More information

\title{
Cognitive Limitations in Aging and Psychopathology
}

This book examines the major progress made in recent psychological science in understanding the cognitive control of thought, emotion, and behavior and what happens when that control is diminished as a result of aging, depression, developmental disabilities, or psychopathology. Each chapter of this volume reports the most recent research by a leading researcher on the international stage. Topics include the effects on thought, emotion, and behavior by limitations in working memory, cognitive control, attention, inhibition, and reasoning processes. Other chapters review standard and emerging research paradigms and new findings on limitations in cognitive functioning associated with aging and psychopathology. The explicit goal behind this volume was to facilitate cross-area research and training by familiarizing researchers with paradigms and findings in areas different from, but related to, their own.

Randall W. Engle is Professor and Chair in the School of Psychology at Georgia Institute of Technology. He received his M.A. and Ph.D. from Ohio State University. His research over the past 20 years has evolved from that regarding the nature of individual differences in working memory capacity (WMC) to the role of WMC in higher-order cognition.

Grzegorz Sedek is Director of the Institute of Social Psychology at Warsaw School of Social Psychology in Poland and professor at the Institute of Psychology, Polish Academy of Sciences. He received his M.A. and Ph.D. from the University of Warsaw in Poland. His main areas of research involve cognitive limitations in depression, aging, after uncontrollability pre-exposure, and dual-process models in social cognition.

Ulrich von Hecker is Lecturer at the School of Psychology at Cardiff University. His current research involves social cognition, cognitive limitations in depression, and the nature and the dynamic character of emotion. He has written many articles and has published in the Journal of Experimental Psychology, European Journal of Social Psychology, and Social Cognition.

Daniel N. McIntosh is Associate Professor of Psychology at the University of Denver. His research focuses on emotions and coping using survey, laboratory, and psychophysiological methods. In particular, he investigates the role of religion in coping, stress and coping in low control contexts, and cognitive deficits emerging from situations of uncontrollability and depression. 
Cambridge University Press

978-0-521-83407-0 - Cognitive Limitations in Aging and Psychopathology

Edited by Randall W. Engle, Grzegorz Sedek, Ulrich von Hecker and Daniel N. Mcintosh

Frontmatter

More information

\section{Cognitive Limitations in Aging and Psychopathology}

Edited by

RANDALL W. ENGLE

Georgia Institute of Technology

GRZEGORZ SEDEK

Warsaw School of Social Psychology and

Polish Academy of Sciences

\section{ULRICH VON HECKER}

Cardiff University

DANIEL N. MCINTOSH

University of Denver 
Cambridge University Press

978-0-521-83407-0 - Cognitive Limitations in Aging and Psychopathology

Edited by Randall W. Engle, Grzegorz Sedek, Ulrich von Hecker and Daniel N. Mcintosh

Frontmatter

More information

\section{CAMBRIDGE UNIVERSITY PRESS}

Cambridge, New York, Melbourne, Madrid, Cape Town, Singapore, São Paulo

Cambridge University Press

40 West 20th Street, New York, NY 10011-4211, USA

www.cambridge.org

Information on this title: www.cambridge.org/9780521834070

(C) Cambridge University Press 2005

This publication is in copyright. Subject to statutory exception and to the provisions of relevant collective licensing agreements, no reproduction of any part may take place without the written permission of Cambridge University Press.

First published 2005

Printed in the United States of America

A catalog record for this publication is available from the British Library.

Library of Congress Cataloging in Publication Data.

Cognitive limitations in aging and psychopathology / edited by Randall W.

Engle... [et al.].

p. $\mathrm{cm}$.

Includes bibliographical references and indexes.

ISBN 0-521-83407-4 (hardback) - ISBN 0-521-54195-6 (pbk.)

1. Cognition disorders. 2. Cognition disorders in old age. 3. Developmental disabilities.

4. Psychology, Pathological. 5. Cognition in old age. 6. Cognitive psychology.

7. Cognition. I. Engle, Randall W.

RC553.C64C635 2005

$618.97^{\prime} 68-\mathrm{dc} 22 \quad 2005000124$

ISBN-13 978-0-521-83407-o hardback

ISBN-10 0-521-83407-4 hardback

ISBN-13 978-0-521-54195-4 paperback

ISBN-10 0-521-54195-6 paperback

Cambridge University Press has no responsibility for

the persistence or accuracy of URLs for external or

third-party Internet Web sites referred to in this publication

and does not guarantee that any content on such

Web sites is, or will remain, accurate or appropriate. 
Cambridge University Press

978-0-521-83407-0 - Cognitive Limitations in Aging and Psychopathology

Edited by Randall W. Engle, Grzegorz Sedek, Ulrich von Hecker and Daniel N. Mcintosh

Frontmatter

More information

\section{Contents}

List of Contributors

page vii

Preface

Acknowledgments

1. Cognitive Limitations in Aging and Psychopathology: An Introduction and a Brief Tutorial to Research Methods Randall W. Engle, Grzegorz Sedek, Ulrich von Hecker, and Daniel N. McIntosh

\section{SECTION I WORKING MEMORY AND COGNITIVE FUNCTIONS}

2. Working Memory Capacity in Hot and Cold Cognition Nash Unsworth, Richard P. Heitz, and Randall W. Engle

3. Age Differences and Individual Differences in Cognitive Functions Klaus Oberauer

4. Stress and Working Memory: Between-Person and Within-Person Relationships

Martin Sliwinski, Joshua Smyth, Robert S. Stawski, and Christina Wasylyshyn

\section{SECTION II AGING AND PSYCHOPATHOLOGY OF} COGNITIVE CONTROL

5. The Aging of Cognitive Control: Studies of Conflict Processing, Goal Neglect, and Error Monitoring Robert West and Ritvij Bowry

6. Cognitive Control and Schizophrenia: Psychological and Neural Mechanisms

Deanna M. Barch and Todd S. Braver 
Cambridge University Press

978-0-521-83407-0 - Cognitive Limitations in Aging and Psychopathology

Edited by Randall W. Engle, Grzegorz Sedek, Ulrich von Hecker and Daniel N. Mcintosh

Frontmatter

More information

7. Aging and Varieties of Cognitive Control: A Review of Meta-Analyses on Resistance to Interference, Coordination, and Task Switching, and an Experimental Exploration of Age-Sensitivity in the Newly Identified Process of Focus Switching

Paul Verhaeghen, John Cerella, Kara L. Bopp, and Chandramallika Basak

8. An Ecological Approach to Studying Aging and Dual-Task Performance Karen Z. H. Li, Ralf Th. Krampe, and Albina Bondar

9. Cognitive Performance After Preexposure to Uncontrollability and in a Depressive State: Going with a Simpler "Plan B"

Daniel N. McIntosh, Grzegorz Sedek, Susan Fojas, Aneta Brzezicka-Rotkiewicz, and Miroslaw Kofta

SECTION III ATTENTION, INHIBITION, AND

REASONING PROCESSES

10. The Nature of Attentional Bias in Human Anxiety Elaine Fox and George A. Georgiou

11. Inhibition, Rumination, and Mood Regulation in Depression Jutta Joormann

12. Aging and Inhibitory Processes in Memory, Attentional, and Motor Tasks

Elizabeth A. Maylor, Friederike Schlaghecken, and Derrick G. Watson

13. Impairments of Memory and Reasoning in Patients with Neuropsychiatric Illness: Disruptions of Dynamic Cognitive Binding? James A. Waltz

14. Generative Reasoning as Influenced by Depression, Aging, Stereotype Threat, and Prejudice Ulrich von Hecker, Grzegorz Sedek, Kinga Piber-Dabrowska, and Sylwia Bedynska

Name Index 
Cambridge University Press

978-0-521-83407-0 - Cognitive Limitations in Aging and Psychopathology

Edited by Randall W. Engle, Grzegorz Sedek, Ulrich von Hecker and Daniel N. Mcintosh

Frontmatter

More information

\section{Contributors}

Deanna M. Barch

Department of Psychology

Washington University

Campus Box 1125

One Brookings Drive

St. Louis, MO 63130

e-mail: dbarch@artsci.wustl.edu

\section{Chandramallika Basak}

Department of Psychology and

Center for Health and Behavior Syracuse University 430 Huntington Hall

Syracuse, NY 13210

e-mail: cbasak@syr.edu

\section{Sylwia Bedynska}

Warsaw School of Social

Psychology

Chodakowska 19/31

03-815 Warsaw

Poland

e-mail: bedynska@pro.onet.pl

\section{Albina Bondar}

Max Planck Institute for Human

Development

Center for Lifespan Psychology

Lentzeallee 94 D-14195 Berlin

Germany e-mail:

bondar@mpib-berlin.mpg.de

\section{Kara L. Bopp}

Department of Psychology

Hamilton College

198 College Hill Road

Clinton, NY 13323

kbopp@hamilton.edu

\section{Ritvij Bowry}

118 Haggar Hall

University of Notre Dame

Notre Dame, IN 46556

e-mail: Ritvij.Bowry.1@nd.edu

\section{Todd S. Braver}

Department of Psychology

Washington University

Campus Box 1125

One Brookings Drive

St. Louis, MO 63130

e-mail: tbraver@artsci.wustl.edu

\section{Aneta Brzezicka-Rotkiewicz}

Warsaw School of Social

Psychology

Chodakowska 19/31

03-815 Warsaw

Poland

e-mail: abrzezi2@swps.edu.pl 
Cambridge University Press

978-0-521-83407-0 - Cognitive Limitations in Aging and Psychopathology

Edited by Randall W. Engle, Grzegorz Sedek, Ulrich von Hecker and Daniel N. Mcintosh

Frontmatter

More information

viii

Contributors

\section{John Cerella}

Department of Psychology and

Center for Health and Behavior

Syracuse University

430 Huntington Hall

Syracuse, NY 13210

e-mail: jcerella@psych.syr.edu

\section{Randall W. Engle}

School of Psychology

Georgia Institute of Technology

654 Cherry Street

Atlanta, GA 30332-0170

e-mail:

randall.engle@psych.gatech.edu

\section{Susan Fojas}

Department of Psychology

University of Denver

Denver, CO 80208

e-mail: fojass@jccany.org

\section{Elaine Fox}

Department of Psychology

University of Essex

Wivenhoe Park

Colchester $\mathrm{CO}_{4}{ }_{3} \mathrm{SQ}$

United Kingdom

e-mail: efox@essex.ac.uk

\section{George A. Georgiou}

School of Humanities and Social

Sciences

Intercollege

46 Makedonitissas Avenue

P.O. Box 24005

1700 Nicosia

Cyprus

e-mail:

georgiou.g@intercollege.ac.cy

\section{Richard P. Heitz}

School of Psychology

Georgia Institute of Technology

654 Cherry Street

Atlanta, GA 30332-0170

e-mail: gteo16z@prism.gatech.edu

\section{Jutta Joormann}

Department of Psychology

Bldg. 420 Jordan Hall, Room 160

Stanford University

Stanford, CA 94305

e-mail:

joormann@psych.stanford.edu

\section{Miroslaw Kofta}

Faculty of Psychology

University of Warsaw

Stawki 5/7 Warsaw

Poland

e-mail:

kofta@engram.psych.uw.edu.pl

\section{Ralf Th. Krampe}

Max Planck Institute for Human

Development

Center for Lifespan Psychology

Lentzeallee 94 D-14195 Berlin

Germany

e-mail:

krampe@mpib-berlin.mpg.de

\section{Karen Z. H. Li}

Centre for Research in Human

Development

Department of Psychology

Concordia University

7141 Sherbrooke Street West

Montreal, Quebec

Canada $\mathrm{H}_{4} \mathrm{~B}$ 1 R6

e-mail: kli@vax2.concordia.ca

\section{Elizabeth A. Maylor}

Department of Psychology

University of Warwick

Coventry $\mathrm{CV}_{4} 7 \mathrm{AL}$

United Kingdom

e-mail:

Elizabeth.Maylor@warwick.ac.uk

\section{Daniel N. McIntosh}

Department of Psychology

University of Denver 
Cambridge University Press

978-0-521-83407-0 - Cognitive Limitations in Aging and Psychopathology

Edited by Randall W. Engle, Grzegorz Sedek, Ulrich von Hecker and Daniel N. Mcintosh

Frontmatter

More information

\section{Contributors}

Denver, CO 80208

e-mail:dmcintos@du.edu

\section{Klaus Oberauer}

University of Potsdam

Allgemeine Psychologie I

Postfach 601553

14415 Potsdam

Germany

e-mail: ko@rz.uni-potsdam.de

\section{Kinga Piber-Dabrowska}

Warsaw School of Social

Psychology

Chodakowska 19/31

03-815 Warsaw

Poland

e-mail: kinga.piberdabrowska@swps.edu.pl

\section{Friederike Schlaghecken}

Department of Psychology

University of Warwick

Coventry $\mathrm{CV}_{4} 7 \mathrm{AL}$

United Kingdom

e-mail:

F.Schlaghecken@warwick.ac.uk

\section{Grzegorz Sedek}

Warsaw School of Social

Psychology and Polish

Academy of Sciences

Chodakowska 19/31

03-815 Warsaw

Poland

e-mail:

Grzegorz.Sedek@swps.edu.pl

\section{Martin Sliwinski}

Department of Psychology

Huntington Hall 430

Syracuse University

Syracuse, NY 13244

e-mail: mjsliwin@psych.syr.edu

\section{Joshua Smyth}

Department of Psychology

Huntington Hall 430

Syracuse University

Syracuse, NY 13244

e-mail: jmsmyth@psych.syr.edu

\section{Robert S. Stawski}

Department of Psychology

Huntington Hall 430

Syracuse University

Syracuse, NY 13244

e-mail: rsstawski@syr.edu

\section{Nash Unsworth}

School of Psychology

Georgia Institute of Technology

654 Cherry Street

Atlanta, GA 30332-0170

e-mail: gtgo39d@prism.gatech.edu

\section{Paul Verhaeghen}

Department of Psychology and

Center for Health and Behavior

Syracuse University

430 Huntington Hall

Syracuse, NY 13210

e-mail: pverhaeg@psych.syr.edu

\section{Ulrich von Hecker}

School of Psychology

Cardiff University

P.O. Box 901

Cardiff, CFio 3 YG

United Kingdom

e-mail: vonheckeru@cardiff.ac.uk

\section{James A. Waltz}

University of Maryland School of

Medicine

Maryland Psychiatric Research

\section{Center}

P. O. Box 21247

Baltimore, MD 21228

e-mail:

jwaltz@mprc.umaryland.edu 
Cambridge University Press

978-0-521-83407-0 - Cognitive Limitations in Aging and Psychopathology

Edited by Randall W. Engle, Grzegorz Sedek, Ulrich von Hecker and Daniel N. Mcintosh Frontmatter

More information

\section{Christina Wasylyshyn}

Department of Psychology

Huntington Hall 430

Syracuse University

Syracuse, NY 13244

e-mail: cwasylys@syr.edu

\section{Derrick G. Watson}

Department of Psychology

University of Warwick
Coventry $\mathrm{CV}_{4} 7 \mathrm{AL}$

United Kingdom

e-mail:

D.G.Watson@warwick.ac.uk

\section{Robert West}

118 Haggar Hall

University of Notre Dame

Notre Dame, IN 46556

e-mail:west.19@nd.edu 
Cambridge University Press

978-0-521-83407-0 - Cognitive Limitations in Aging and Psychopathology

Edited by Randall W. Engle, Grzegorz Sedek, Ulrich von Hecker and Daniel N. Mcintosh

Frontmatter

More information

\section{Preface}

As technological advances lead to more understanding of the brain, or the "hardware" of human thought, the importance of understanding the "software" that is, cognitive functions, has become even more important. There has been progress in the cognitive sciences in understanding the basic processes of cognition and how these processes relate to the operations and behaviors of the organism in the environment. Among the most intensely studied processes are those relating to attention and working memory (e.g., inhibition, updating, and coordination) and higher level cognitive abilities such as planning, reasoning, comprehension, and problem solving, which are attributed to circuits associated with the brain's frontal lobe. One reason for this accelerating interest is the rapid progress in those areas of cognitive psychology and cognitive neuroscience that focus on working memory and neuroimaging research (Andrade, 2001; Cabeza \& Nyberg, 2000; Davidson, Pizzagalli, Nitschke, \& Putnam, 2002; Gazzaniga, Ivry, \& Mangum, 1998; Logie \& Gilhooly, 1999; Miyake \& Shah, 1999; Richardson et al., 1996). Another reason for this surge of interest is that many populations, such as older adults (Craik \& Salthouse, 2000; Perfect \& Maylor, 2000; Rabbitt, 1997), persons with emotional disorders (Hertel, 1997; von Hecker \& Sedek, 1999; Williams, Watts, MacLeod, \& Mathews, 1997), and individuals with brain injuries (Waltz et al., 1999), have demonstrated cognitive limitations with respect to attention, working memory, and other so-called executive functions.

The significance of these functions is underscored by the wide range of populations in which such impairments have been found and by the areas of specialization within the cognitive sciences in which they have become increasingly important. In this broad interdisciplinary research domain, one might distinguish, on the one hand, basic research fostering the understanding of cognitive processes, and, on the other hand, research fields that combine those recent advances in cognitive psychology with the investigation into individual or group differences. Such individual 
Cambridge University Press

978-0-521-83407-0 - Cognitive Limitations in Aging and Psychopathology

Edited by Randall W. Engle, Grzegorz Sedek, Ulrich von Hecker and Daniel N. Mcintosh

Frontmatter

More information

differences might be associated with developmental changes such as aging, developmental problems such as reading disability, and psychopathology such as depression and schizophrenia. For example, cognitive aging links the research lines on aging to those on cognitive processes. Similarly, studies in cognitive psychopathology examine emotional, mental, and brain disorders in terms of the underlying basic cognitive mechanisms that are affected in these states. Unfortunately, the literatures in these affiliated fields tend to evolve and progress largely separate from each other, although they share common concepts and objectives and are tightly linked by their central objective to obtain insights into cognitive functions. Explanations of the effects of aging and psychopathology on cognitive performance often make use of concepts from the basic cognitive literature; however, contributors to the two literatures do not often communicate directly with one another. This lack of communication means that insights and information gained from scientists working with one population, or with a particular paradigm, often do little to advance understanding in other closely related areas.

Our experience is that discussions across disciplines provide inspiration that help focus and develop our own understanding and research. The goal of the present volume is to provide such stimulation to others working in the large area of the cognitive sciences. This volume is unique in that it is an original attempt to combine a range of recent research achievements of North American and European teams fostering innovative experimental investigations in the previously mentioned fields. The publication of the volume was motivated by an international, interdisciplinary conference in Kazimierz Dolny, Poland, in autumn 2002, during which most of the chapter authors presented and discussed their work. Unlike larger conferences during which scientists communicate primarily with those working in their own areas of specialization, this conference focused on the presentation and discussion of cutting-edge paradigms and findings from each others' areas, and listening to the thoughts of "outsiders" regarding one's own work. The presenters came from different backgrounds with substantial overlap, such as the emotion-cognition link (Elaine Fox, Jutta Joormann, Edward Necka, Grzegorz Sedek), working memory (Randall Engle, Akira Miyake, Klaus Oberauer, James Waltz), social cognition (Miroslaw Kofta, Daniel McIntosh, Ulrich von Hecker), and cognitive aging (Elizabeth Maylor, Ralf Krampe, Paul Verhaeghen, Patrick Rabbitt).

The aim of the conference was to bring together scholars from different but intersecting fields in an environment that engendered dialogue and understanding of problems common to the intersecting areas. The beautiful Polish countryside and wonderful Polish food and vodka served to lubricate and stimulate the easy flow of ideas across the participants. In terms of this dialogue, for example, cognitive functioning and adaptation were addressed in the context of basic research on working memory and 
Cambridge University Press

978-0-521-83407-0 - Cognitive Limitations in Aging and Psychopathology

Edited by Randall W. Engle, Grzegorz Sedek, Ulrich von Hecker and Daniel N. Mcintosh

Frontmatter

More information

in various attempts to understand specific psychological states. Anxiety, depression, older age, or the experience of social stigmatization, to name just a few examples, can change the way we memorize, reason, or make judgments. Conversely, knowledge about these functional changes might again inform theories about working memory and social cognition in general. The speakers at the conference, and mostly the authors of the present volume, focused their contributions on the relation between the allocated amount of attentional resources and particular modes of processing and on how certain patterns of executive functioning may directly characterize certain states, such as anxiety, depression (dysphoria), or activated stereotypes. They also talked about different candidate functions within current models of working memory, such as attention, maintenance, or inhibition, to better understand the mechanisms of how psychological states might affect thinking and judgment.

In an attempt to further strengthen the theoretical and empirical scope of the volume along the lines discussed at the conference, we invited a number of further authors who are leading experts on related fields, but had not been part of our meetings, to share their views and contribute chapters. We are especially delighted to have received enthusiastic feedback to this invitation and thus be able to include Barch and Braver's chapter on impairments of cognitive control in schizophrenia; Sliwinski, Smyth, Stawski, and Wasylyshyn's chapter on the relation between stress experience and working memory performance; and West and Bowry's chapter on cognitive neuroscience methodologies applied to cognitive aging.

Our aim was to produce a work with chapters that meet the highest demands of accuracy and currency within specializations, but that is accessible to scientists and students outside the authors' specialties. To accomplish this aim, all chapters were reviewed not only by the external reviewers (professionals from the same research field) but also by graduate students who were specialists in areas other than the chapter they reviewed. We believe that those currently working in one area will find the chapters from researchers both inside and outside their area relevant and stimulating. We also believe that students of any of the cognitive sciences will benefit from exposure to both "hot cognition" and "cold cognition" perspectives represented here. We hope readers will find this volume as informative, stimulating, and generative as we found both the conference and the reading of these chapters.

Autumn 2004

Randall W. Engle

(Georgia Institute of Technology, USA)

Grzegorz Sedek

(Warsaw School of Social Psychology

and Polish Academy of Sciences, Poland) 
Cambridge University Press

978-0-521-83407-0 - Cognitive Limitations in Aging and Psychopathology

Edited by Randall W. Engle, Grzegorz Sedek, Ulrich von Hecker and Daniel N. Mcintosh

Frontmatter

More information

xiv

Preface

Ulrich von Hecker

(Cardiff University, UK)

Daniel N. McIntosh

(University of Denver, USA)

\section{References}

Andrade, J. (Ed.). (2001). Working memory in perspective. Hove, UK: Psychology Press.

Cabeza, R., \& Nyberg, L. (2000). Imaging cognition II: An empirical review of 275 PET and fMRI studies. Journal of Cognitive Neuroscience, 12, 1-47.

Craik, F. I. M., \& Salthouse, T. A. (2000). The handbook of aging and cognition. Mahwah, NJ: Lawrence Erlbaum Associates.

Davidson, R. J., Pizzagalli, D., Nitschke, J. B., \& Putnam, K. (2002). Depression: Perspective from affective neuroscience. Annual Review of Psychology, 53, 545574 .

Hertel, P. T. (1997). On the contributions of deficient cognitive control to memory impairments in depression. Cognition and Emotion, 11, 569-583.

Logie, R. H., \& Gilhooly, K. J. (Eds.). (1999). Working memory and thinking. Hove, UK: Psychology Press.

Miyake, A., \& Shah, P. (Eds). (1999). Models of working memory: Mechanism of active maintenance and executive control. New York: Cambridge University Press.

Perfect, T. J., \& Maylor, E. A. (2000). Models of cognitive aging. New York: Oxford University Press.

Rabbitt, P. M. A. (1997). Methodologies for frontal and executive function. Hove, UK: Lawrence Erlbaum Associates.

Richardson, J. T. E., Engle, R. W., Hasher, L., Logie, R., Stolzfus, E., \& Zacks, R. (Eds.). (1996). Working memory and human cognition. New York: Oxford University Press. von Hecker, U., \& Sedek, G. (1999). Uncontrollability, depression, and mental models in the social domain. Journal of Personality and Social Psychology, 77, 833-850.

Waltz, J. A., Knowlton, B. J., Holyoak, K. J., Boone, K. B., Mishkin, F. S., de Menezes Santos, M., Thomas, C. R., \& Miller, B. L. (1999). A system for relational reasoning in human prefrontal cortex. Psychological Science, 10, 119-125.

Williams, J. M. G., Watts, F. N., MacLeod, C., \& Mathews, A. (1997). Cognitive psychology and emotional disorders. Chichester: Wiley. 
Cambridge University Press

978-0-521-83407-0 - Cognitive Limitations in Aging and Psychopathology

Edited by Randall W. Engle, Grzegorz Sedek, Ulrich von Hecker and Daniel N. Mcintosh

Frontmatter

More information

\section{Acknowledgments}

The editors owe thanks to a number of people, organizations, and institutions. Without their help and support, it would not have been possible to complete this book.

First, we express our thanks to various granting agencies that supported our research and indeed the completion of our editing work. Randall Engle was supported by Grant F49620-00-1-131 from the Air Force Office of Scientific Research. Grzegorz Sedek was supported by the Polish Committee for Scientific Research (grant 5 Ho1F 013 21). Ulrich von Hecker was supported by the German National Research Foundation (grant He 2225) and by the Economic and Social Research Council (grant RES-ooo-23-0496). Daniel McIntosh was supported by the Walter Rosenberry Fund and Office of Internationalization at the University of Denver. The Warsaw School of Social Psychology provided financial and logistic help in organizing and running our conference in Kazimierz Dolny. Very obviously, much expertise and enthusiasm went into selecting and preparing such a wonderful, stimulating location for our meeting. In this respect, we thank all members of the local organizing committee, especially Aneta Brzezicka-Rotkiewicz, Sylwia Bedynska, Izabela Krejtz, and Kinga Piber-Dabrowska.

Akira Miyake, Edward Necka, and Patrick Rabbitt gave presentations at the conference and shared highly stimulating ideas in the discussions. They did not contribute to the present volume, but we highly appreciated their input and company.

We would also like to express thanks to all those who read, reviewed, and commented on draft papers that led to the final chapters published in this book. This includes not only peers and colleagues but also graduate students at several universities. We feel that the book as a whole has hugely benefited from the expertise and the feedback of these early readers, the communication among authors and readers, and among author groups from different chapters. All of these communications have in fact sparked many ideas for innovative research. Communication was made easy and 
Cambridge University Press

978-0-521-83407-0 - Cognitive Limitations in Aging and Psychopathology

Edited by Randall W. Engle, Grzegorz Sedek, Ulrich von Hecker and Daniel N. Mcintosh

Frontmatter

More information

xvi

Acknowledgments

enjoyable by a Web site that was opened specifically for the purpose of exchanging views and arguments about the chapters and their draft versions during the time of writing. This Web site was professionally set up and managed by Tomasz Grzelka, whom we thank wholeheartedly. And, of course, our thanks go to the authors of all chapters, all of whom cooperated in a constructive way, preparing two or three drafts upon receiving editorial comments and collegial criticism.

We sincerely thank Philip Laughlin from Cambridge University Press for smoothly guiding the whole book project and for many helpful suggestions during the editorial process. Rhiannon Buck language-edited and commented on drafts of various parts of the book. Wiola Wisniewska, Ewa Lipiec, and Rafal Albinski provided valuable help with technical issues of editing. 